\title{
Registry report on prediction by Pocock cardiovascular score of cerebral microemboli acutely following carotid endarterectomy
}

\author{
Mahmud Saedon, ${ }^{1,2}$ Athanasios Saratzis, ${ }^{3}$ Rachel W S Lee, ${ }^{2}$ \\ Charles E Hutchinson, ${ }^{2}$ Christopher H E Imray, ${ }^{2}$ Donald R J Singer ${ }^{4,5}$
}

To cite: Saedon M, Saratzis A, Lee RWS, et al. Registry report on prediction by Pocock cardiovascular score of cerebral microemboli acutely following carotid endarterectomy. Stroke and Vascular Neurology 2018;3: e000116. doi:10.1136/svn2017-000116

Received 6 0ctober 2017 Revised 10 November 2017 Accepted 12 November 2017 Published Online First 9 March 2018
Check for updates

${ }^{1}$ Nottingham University Hospitals NHS Trust, Nottingham, UK ${ }^{2}$ University Hospitals Coventry and Warwickshire NHS Trust, Coventry, UK

${ }^{3}$ Leicester Royal Infirmary, Leicester, UK

${ }^{4}$ Yale School of Medicine, New Haven, Connecticut, USA

${ }^{5}$ Fellowship of Postgraduate Medicine, London, UK

Correspondence to Professor Donald R J Singer: fpm.chandos@gmail.com

\section{ABSTRACT}

Background Cerebral microemboli may lead to ischaemic neurological complications after carotid endarterectomy (CEA). The association between classical cardiovascular risk factors and acute cerebral microemboli following carotid surgery has not been studied. The aim of this study was to explore whether an established cardiovascular risk score (Pocock score) predicts the presence of cerebral microemboli acutely after CEA.

Subjects and methods Pocock scores were assessed for the 670 patients from the Carotid Surgery Registry (age $71 \pm 1$ (SEM) years, 474 (71\%) male, 652 (97\%) Caucasian) managed from January 2002 to December 2012 in the Regional Vascular Centre at University Hospitals Coventry and Warwickshire NHS Trust, which serves a population of 950000 . CEA was undertaken in $474(71 \%)$ patients for symptomatic carotid stenosis and in $196(25 \%)$ asymptomatic patients during the same period. $74 \%$ of patients were hypertensive, $71 \%$ were smokers and $49 \%$ had hypercholesterolaemia.

Results A high Pocock score $(\geq 2.3 \%)$ was significantly associated with evidence of cerebral microemboli acutely following CEA ( $P=0.039$, Mann-Whitney (MW) test). A Pocock score $(\geq 2.3 \%)$ did not predict patients who required additional antiplatelet therapy (microemboli signal (MES) rate $>50$ hour $^{-1}: \mathrm{P}=0.164$, MW test). Receiver operating characteristic analysis also showed that the Pocock score predicts acute postoperative microemboli (area under the curve (AUC) $0.546,95 \% \mathrm{Cl} 0.502$ to $0.590, \mathrm{P}=0.039$ ) but not a high rate of postoperative microemboli (MES $>50$ hour $^{-1}$ : AUC $0.546,95 \% \mathrm{Cl} 0.482$ to $0.610, \mathrm{P}=0.164$ ). A Pocock score $\geq 2.3 \%$ showed a sensitivity of $74 \%$ for the presence of acute postoperative cerebral microemboli. A Pocock score $\geq 2.3 \%$ also showed a sensitivity of $77 \%$ and a negative predictive value of $90 \%$ for patients who developed a high microembolic rate $>50$ hour $^{-1}$ after carotid surgery.

Conclusion These findings demonstrate that the Pocock score could be used as a clinical tool to identify patients at high risk of developing acute postoperative microemboli.

\section{INTRODUCTION}

Patients with symptomatic atherosclerotic carotid artery disease typically have a cluster of classical cardiovascular risk factors. ${ }^{12}$ Patients with carotid artery disease have been shown to be at an increased risk of myocardial infarction and death related to ischaemic heart disease, and a greater risk of death from myocardial infarction than stroke. ${ }^{1}$ A number of composite risk scores have been developed to estimate the risk of patients developing cardiovascular disease (CVD), based on the presence of cardiovascular risk factors and established clinical vascular disease. These estimated CVD risk scores have been widely advocated $^{3}$ as tools to support introduction and use of medical interventions such as prescribing antiplatelet, antihypertensive and lipid-lowering agents. ${ }^{2}$

The Pocock cardiovascular score was developed to predict the 5-year risk of death from CVD. The score was derived from cardiovascular risk factor data from 47088 participants from eight published randomised controlled trials of antihypertensive treatment. ${ }^{4}$ The Pocock score has the advantage of including weightings for the presence of clinical vascular disease. ${ }^{4}$ Therefore, it is the most suitable CVD risk score to assess the cardiovascular risk factor burden of patients with symptomatic carotid artery disease.

Transcranial Doppler (TCD)-detected microemboli have provided direct evidence of thromboembolism as the main mechanism of stroke syndrome in symptomatic carotid artery disease. ${ }^{5}$ Microemboli present acutely following carotid endarterectomy (CEA) have been demonstrated to be associated with postoperative thromboembolic stroke. ${ }^{6}$ The presence of a high microembolic signal rate acutely after surgery predicts both stroke alone and stroke/transient ischaemic attack (TIA). ${ }^{7}$

There is no current evidence on whether composite cardiovascular risk scores are associated with the presence of microemboli. Additionally, there has been no attempt to associate the severity of cardiovascular risk at baseline with occurrence of postoperative microemboli 
in patients undergoing CEA. Microemboli present acutely after carotid surgery are associated with an increased risk of postoperative stroke syndromes. ${ }^{7}$ However, the current gold standard, TCD imaging, is not widely available in clinical services. ${ }^{8}$ We therefore aimed to explore whether the Pocock cardiovascular score is helpful in predicting the risk of cerebral microemboli acutely after CEA.

\section{SUBJECTS AND METHODS}

Data in this report are from the Carotid Surgery Registry of patients managed in the Regional Vascular Centre at University Hospitals Coventry and Warwickshire NHS Trust, which serves a population of 950000 . Results are for the 670 Registry patients treated from January 2002 to December 2012. The inclusion criteria were patients with evidence of haemodynamically significant carotid stenosis $\geq 50 \%$ on carotid duplex and undergoing CEA. Since 2002, as part of our policy, all patients who underwent CEA had an additional postoperative TCD examination to detect cerebral microemboli, as this cohort of patients merits more aggressive treatment to prevent stroke. ${ }^{9}$

\section{Pocock cardiovascular risk score}

Pocock scores were calculated using the online calculator (http://www.riskscore.org.uk/). The risk score is an integer, with points added for each cardiovascular risk factor. The risk score includes age, gender, systolic blood pressure (BP), serum total cholesterol, height, creatinine, smoking, diabetes, left ventricular hypertrophy, history of stroke and history of myocardial infarction. ${ }^{4}$ The 5-year risk of death from CVD for scores of 10, 20, 30, 40, 50 and 60 was estimated as $0.1 \%, 0.3 \%, 0.8 \%, 2.3 \%, 6.1 \%$ and $15.6 \%$, respectively. ${ }^{4}$ The Pocock risk score is based on a large cohort of randomised controlled trials in different countries with reliable follow-up and has been validated. ${ }^{4}$ Therefore, the risk estimates are more precise in patients with clinical vascular disease than other risk scores. ${ }^{4}$ It is therefore a suitable CVD risk score with which to assess the cardiovascular risk factor burden of patients with symptomatic carotid artery disease.

\section{Cardiovascular risk factors and other definitions}

Definitions for all cardiovascular risk factors, including hypertension, hyperlipidaemia, and major and minor cardiovascular and cerebral events, were based on the Joint British Societies' Guidelines on Prevention of Cardiovascular Disease in Clinical Practices. ${ }^{10}$

\section{Postoperative outcomes}

All the postoperative outcomes were defined based on recommendations of the UK intervention Audit Steering Committee of the Royal College of Physicians. ${ }^{11}$ We defined cumulative major events as the combination of perioperative stroke or transient ischaemic attack, myocardial infarction and death, and cumulative minor events as the combination of neck haematoma and cranial nerve injuries.

\section{Carotid endarterectomy}

CEA was performed as previously reported. ${ }^{12}$ Aspirin $75 \mathrm{mg}$ oral, clopidogrel $75 \mathrm{mg}$ oral or the combination of both antiplatelet agents in these doses was given before carotid surgery. The decision on preoperative antiplatelet treatment was made by the individual surgeons. Overall, 4 patients were on preoperative anticoagulation, 383 patients were on single antiplatelet agent preoperatively, 270 were on dual and 13 were on triple antiplatelet agents preoperatively.

Shunting was performed if the patient developed focal neurological signs when CEA was performed under local anaesthetic; or in those cases performed under general anaesthetic when the mean velocity in the middle cerebral artery dropped by $>50 \%$. All patients received intravenous heparin (40 units $/ \mathrm{kg}$ ) prior to the cross-clamp phase of the CEA. In our study, 465 patients underwent CEA under general anaesthesia and 205 patients were under sedation and local anaesthesia.

\section{TCD recording}

TCD monitoring ${ }^{13}$ was performed (PC Dop 842, SciMed, Bristol, UK) with a $2 \mathrm{MHz}$ probe focused on the middle cerebral artery ipsilateral to the stenotic carotid artery. A head-frame was used to secure a constant angle of insonation during the TCD monitoring. Doppler signals were obtained within the depth range of 55-64 mm and time-averaged mean velocity in the region of $55 \pm 12 \mathrm{~cm} / \mathrm{s}$. We used a single channel and a filter set to a low threshold to capture all possible signals. The recorded ultrasonographic images were then assessed to differentiate artefacts from microemboli based on the criteria of the International Consensus Group on microembolus detection. ${ }^{13}$ Monitoring was performed for a minimum of $30 \mathrm{~min}$ following skin closure. Our vascular technologists in this study had at least 5 years of experience of TCD, ${ }^{14}$ and our observers have $90 \%$ agreement with software validated against a panel of international experts. ${ }^{15}$ The microemboli $^{13}$ rate was calculated at $15 \mathrm{~min}$ intervals. Previously, we added dextran-40 treatment in patients with microemboli signal (MES) rate $>50 /$ hour $^{-16}$. Following our previous work on tirofiban ${ }^{1416}$ (Aggrastat; MSD, Hoddesdon, UK), we have stopped using dextran-40. Currently, all the patients with MES rate $>50 /$ hour $^{-16}$ are given tirofiban intravenously $0.4 \mu \mathrm{g} / \mathrm{kg} / \mathrm{min}$ for $30 \mathrm{~min}$, then $0.1 \mu \mathrm{g} / \mathrm{kg} / \mathrm{min}$ for 18 hours.

\section{Ethics}

Institutional approval was granted. The Research and Development Department at University Hospitals Coventry and Warwickshire NHS Trust (the host institution) confirmed that regional research ethics committee (REC) review was not required under the harmonised Governance Arrangement for REC for research ${ }^{17}$ because this study was considered part of service evaluation. Therefore, patient consent was not required for this study. 
Table 1 Demographic and clinical profile of the 670 patients who underwent carotid endarterectomy

\begin{tabular}{lc}
\hline & $\mathbf{n}(\%)$ \\
\hline Age, mean \pm SEM & $71 \pm 1$ \\
Male & $474(71)$ \\
Caucasian & $652(97)$ \\
\hline South Asian & $18(3)$ \\
Hypertension & $496(74)$ \\
\hline Never smoked & $196(29)$ \\
Current smoker & $133(20)$ \\
Ex-smoker & $341(51)$ \\
Ischaemic heart disease & $219(33)$ \\
\hline Type 2 diabetes mellitus & $123(18)$ \\
Hypercholesterolaemia & $327(49)$ \\
\hline Peripheral arterial disease & $98(15)$ \\
Cerebrovascular disease & $144(22)$ \\
Family history of cardiovascular disease & $126(19)$ \\
\hline
\end{tabular}

\section{Statistical analysis}

Statistical analyses were conducted using SPSS V.19.

Parametric data are expressed as mean and SEM. Non-parametric data are expressed as median and IQR. Non-parametric unpaired data were analysed using the Mann-Whitney (MW) U test for between-group comparisons. Categorical variables were analysed using the $\chi^{2}$ test or Fisher's exact test. A P value of less than 0.05 was considered significant.

All the patients included in this study were eligible for Pocock score estimation as high-risk patients with clinical CVD. For the analysis, a score of $\geq 2.3 \%$ is taken as the threshold for 'high risk' patients. The association between microemboli and Pocock risk scores $\geq 2.3 \%$ was analysed using the receiver operating characteristic (ROC) curves.

\section{RESULTS}

\section{Clinical data}

Between January 2002 and December 2012, 670 patients were included (mean age: $71 \pm 1$ (SEM) years, $474(71 \%)$ male and 652 (97\%) Caucasian). Co-morbid conditions at baseline and indications for CEA are listed in tables 1 and 2. CEA was undertaken in $474(71 \%)$

\begin{tabular}{lc}
\hline Table 2 & Indications for carotid endarterectomy \\
\hline Indications & n (\%) \\
\hline Transient ischaemic attack & $251(38)$ \\
\hline Minor stroke & $125(19)$ \\
\hline Amaurosis fugax & $76(11)$ \\
\hline Retinal artery occlusion & $22(3)$ \\
\hline Asymptomatic with carotid artery critical stenosis & $166(25)$ \\
\hline Pre or post coronary artery bypass grafting & $30(5)$ \\
\hline
\end{tabular}

Table 3 30-Day complications of 670 patients who underwent carotid endarterectomy

\begin{tabular}{lr}
\hline Complications & $\mathbf{n ~ ( \% ~ ( 9 5 \% ~ C l ) ) ~}$ \\
\hline Cerebrovascular accident & $16(2.4(1.24$ to 3.56$))$ \\
\hline Myocardial infarction & $9(1.3(0.44$ to 2.16$))$ \\
\hline $\begin{array}{l}\text { Death } \\
\text { Neck haematoma }\end{array}$ & $13(1.9(0.87$ to 2.93$))$ \\
$\begin{array}{l}\text { Cranial nerve injury } \\
\begin{array}{l}\text { Cumulative major events } \\
\text { (cerebrovascular accident, } \\
\text { myocardial infarction, death) }\end{array} \\
\begin{array}{l}\text { Cumulative minor events (neck } \\
\text { haematoma, cranial nerve injuries) }\end{array}\end{array}$ & $34(5.1(3.43$ to 6.77$))$ \\
\hline
\end{tabular}

patients for symptomatic disease and in 196 (24.8\%) for asymptomatic carotid stenosis. Of the 670 patients, $74 \%$ were hypertensive, $71 \%$ were smokers and $49 \%$ had hypercholesterolaemia (table 1). The mean systolic BP was $145 \pm 1(\mathrm{SEM}) \mathrm{mm} \mathrm{Hg}$, the mean diastolic $\mathrm{BP}$ was $74 \pm 1 \mathrm{~mm} \mathrm{Hg}$, the mean body mass index was $27 \pm 0.2 \mathrm{~kg}$ / $\mathrm{m}^{2}$, and the mean total cholesterol was $4.6 \pm 0.1 \mathrm{mmol} / \mathrm{L}$.

Following CEA, 335 (53\%) patients developed acute postoperative cerebral microemboli. Eighty-six (13\%) patients developed sustained high microembolic rate $\left(\right.$ MES $>50$ hour $^{-1}$ ), for which additional antiplatelet therapy was administered to reduce risk of postoperative stroke, as per the department's standard protocol, using an intravenous tirofiban infusion. ${ }^{9}$ The overall 30-day mortality was $1.9 \%$ (13/670 patients), and 30-day morbidity included cerebrovascular accident or transient ischaemic attack in 16 (2.4\%), myocardial infarction in $9(1.3 \%)$, neck haematoma in $24(3.6 \%)$ and transient cranial nerve injury in $34(5.1 \%)$ patients (table 3). The cumulative 30-day major event rate was $4.3 \%(29 / 670)$ and minor event rate $8.4 \%(56 / 670)$ (table 3$)$.

\section{Pocock risk score}

Patients with evidence of cerebral microemboli acutely following CEA had a significantly higher Pocock score at baseline (microemboli 4.6\% (2.2-9.5) vs non-microemboli $4.2 \%$ (1.7-7.9), $\mathrm{P}=0.03$, MW test; figure 1). The Pocock score was not significantly different between those who developed a sustained high MES rate $>50$ hour $^{-1}$ acutely following CEA requiring additional antiplatelet therapy (tirofiban infusion) and those who did not $(\mathrm{P}=0.164$, MW test $)$. ROC analysis for Pocock score showed accurate prediction of the presence of acute postoperative microemboli (area under the curve (AUC) $0.546,95 \%$ CI 0.502 to $0.590, \mathrm{P}=0.03$; figure 2). However, the score did not predict those with an MES $>50$ hour $^{-1}$ for whom we routinely employ additional antiplatelet therapy (AUC $0.546,95 \%$ CI 0.482 to 0.610 , $\mathrm{P}=0.164$ ). We used a Pocock score of $\geq 2.3 \%$ (which is equal to a score of 10 points) or $\geq 6.1 \%$ as potential cut-off points in identifying those who are more likely to develop microemboli (tables $4 \mathrm{~A}, \mathrm{~B}$ and $5 \mathrm{~A}, \mathrm{~B}$ ). A Pocock score of $\geq 2.3 \%$ showed a relatively high sensitivity $(74.37 \%)$ for the presence of acute 


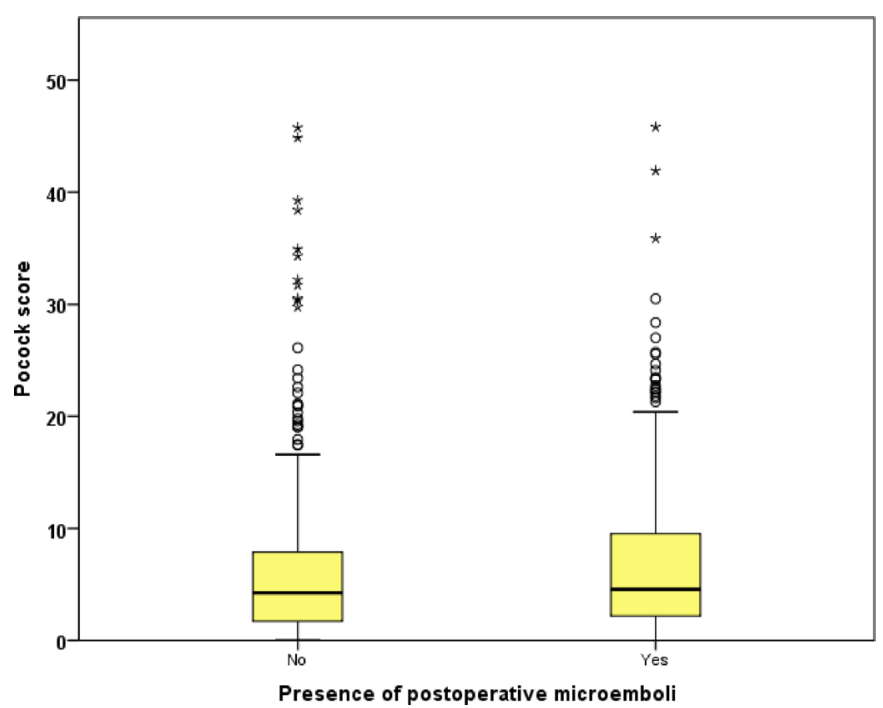

Figure 1 Difference of Pocock score between 355 with postoperative microemboli and 315 without postoperative microemboli who underwent carotid endarterectomy between January 2002 and December 2012.

postoperative cerebral microemboli. It also showed high sensitivity $(76.7 \%)$ and negative predictive value $(89.5 \%)$ for patients who developed a high microembolic rate $>50$ hour $^{-1}$ (tables 4A,B and 5A,B).

\section{DISCUSSION}

This cohort study attempted to assess an established cardiovascular risk score as a means of predicting those who are more likely to develop cerebral microemboli

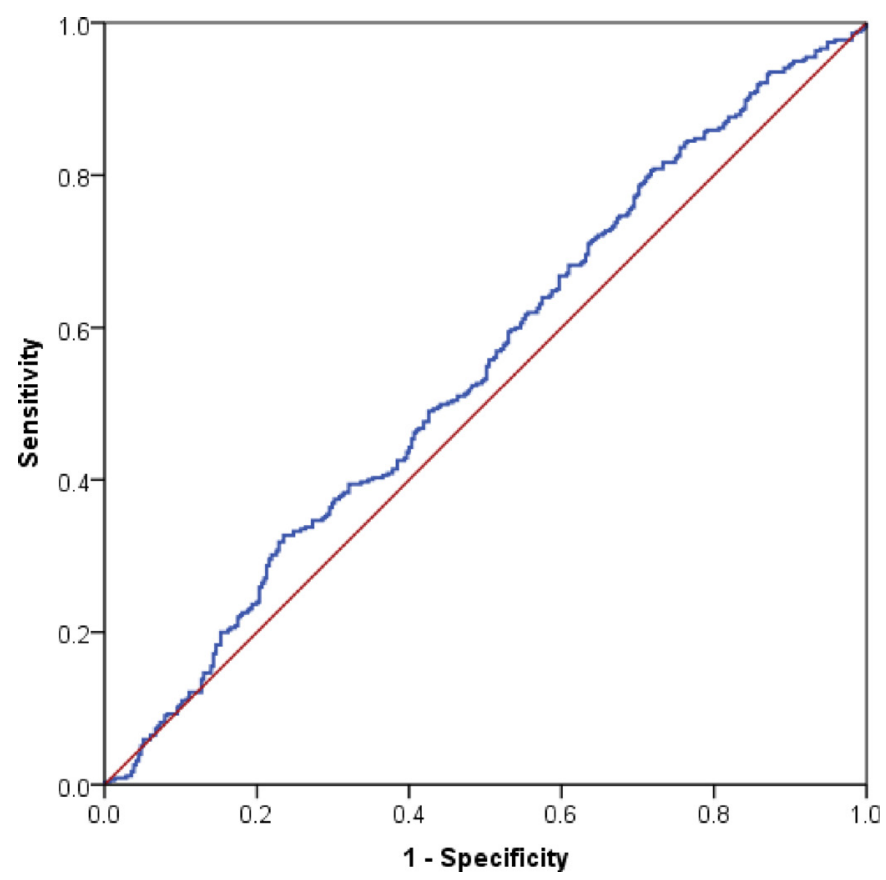

Figure 2 Receiver operating characteristic for Pocock score against presence of microemboli acutely following carotid endarterectomy $(n=670)$ (area under the curve $0.546,95 \% \mathrm{Cl}$ 0.502 to $0.590, P=0.03$ ).
Table 4A Diagnostic accuracy of Pocock score $\geq 2.3 \%$ (score of 40) for microemboli presence

\begin{tabular}{lll}
\hline Criterion & Score & $95 \% \mathrm{Cl}$ \\
\hline Sensitivity & $74.4 \%$ & $95 \% \mathrm{Cl} 69.5$ to 78.8 \\
Specificity & $31.8 \%$ & $95 \% \mathrm{Cl} 26.6$ to 37.2 \\
Positive predictive value & $55.1 \%$ & $95 \% \mathrm{Cl} 50.5$ to 59.6 \\
\hline Negative predictive value & $52.4 \%$ & $95 \% \mathrm{Cl} 45.0$ to 59.6 \\
\hline
\end{tabular}

immediately after carotid surgery. Those with microemboli had a higher Pocock score at baseline. Importantly, a Pocock score $\geq 2.3 \%$ was shown to have relatively high sensitivity and high negative predictive value in detecting those with microemboli and those with a high cerebral MES rate, which has been associated with embolic events. ${ }^{9}$

Stroke, especially in the immediate postoperative period, remains one of the most important complications following successful CEA. The main mechanisms leading to stroke include postoperative hypertension causing hyperperfusion syndrome and thromboembolism from the endarterectomised area or elsewhere. Hyperperfusion syndrome is uncommon and strict postoperative BP control with the provision of written guidance has been shown to minimise this. ${ }^{18} \mathrm{TCD}$ remains the only proven method of predicting post-CEA thromboembolic events. ${ }^{19}$ Multicentre studies have confirmed that acutely persistent microembolisation is associated with a significantly higher short-term stroke risk. ${ }^{6} 12$ 20-23 Clinically, it is unclear which patients will develop acutely persistent microembolisation post carotid surgery. Surgical technical error is not common as a main cause of microembolisation. ${ }^{24}$ Patients who have undergone staged bilateral CEA have been shown to have similar rates of postoperative microembolisation. ${ }^{25} \mathrm{~A}$ randomised clinical trial has also reported that a high rate of postoperative embolisation was unrelated to carotid patch type. ${ }^{26}$ Additionally, observational studies ${ }^{27} 28$ have suggested that postoperative microembolisation is more common in women, which goes against technical error as being the main culprit. To date, the most promising theory has come from Hayes $e t a l,{ }^{29}$ who showed that the high rate of postoperative microembolisation reflected physiologically increased platelet reactivity. Therefore, the cause of the postoperative microembolisation may be related to the inherent characteristics of the patient or the

Table 4B Diagnostic accuracy of Pocock score $\geq 6.1 \%$ (score of 50) for microemboli presence

\begin{tabular}{lll}
\hline Criterion & Score & $\mathbf{9 5 \% ~ C l}$ \\
\hline Sensitivity & $40.8 \%$ & $95 \% \mathrm{Cl} 35.7$ to 46.2 \\
Specificity & $62.9 \%$ & $95 \% \mathrm{Cl} 57.3$ to 68.2 \\
Positive predictive value & $55.3 \%$ & $95 \% \mathrm{Cl} 49.1$ to 61.5 \\
Negative predictive value & $48.5 \%$ & $95 \% \mathrm{Cl} 43.6$ to 53.5 \\
\hline
\end{tabular}


Table 5A Diagnostic accuracy of Pocock score $\geq 2.3 \%$ (score of 40) for microembolic rate $>50$ hour $^{-1}$

\begin{tabular}{lll}
\hline Criterion & Score & $\mathbf{9 5 \% ~ C l}$ \\
\hline Sensitivity & $76.7 \%$ & $95 \% \mathrm{Cl} 66.4$ to 85.2 \\
Specificity & $29.3 \%$ & $95 \% \mathrm{Cl} 25.6$ to 33.2 \\
Positive predictive value & $13.8 \%$ & $95 \% \mathrm{Cl} 10.8$ to 17.2 \\
Negative predictive value & $89.5 \%$ & $95 \% \mathrm{Cl} 84.3$ to 93.5 \\
\hline
\end{tabular}

Table 5B Diagnostic accuracy of Pocock score $\geq 6.1 \%$ (score of 50) for microembolic rate $>50$ hour $^{-1}$

\begin{tabular}{lll}
\hline Criterion & Score & $\mathbf{9 5 \% ~ C l}$ \\
\hline Sensitivity & $44.2 \%$ & $95 \% \mathrm{Cl} 33.5$ to 55.3 \\
Specificity & $61.6 \%$ & $95 \% \mathrm{Cl} 57.6$ to 65.6 \\
Positive predictive value & $14.5 \%$ & $95 \% \mathrm{Cl} 10.5$ to 19.4 \\
Negative predictive value & $88.2 \%$ & $95 \% \mathrm{Cl} 84.7$ to 91.2 \\
\hline
\end{tabular}

atherosclerotic disease process itself. To date, the association between classical cardiovascular risk factors and microemboli acutely following carotid surgery has not been studied. Therefore, a clinical scoring system that would predict the risk of postoperative microemboli would be useful if the outcome were either stroke/ TIA prevention by increasing perioperative treatment and/or by longer term strategy to reduce the severity of factors within the Pocock score contributing to the increased stroke/TIA risk.

One of the key findings of our study is that Pocock score shows an association with the presence of postoperative microemboli. A Pocock score of $\geq 2.3 \%$ was shown to have high sensitivity regarding the presence of microemboli and high negative predictive value regarding a microembolic rate of $>50$ hour $^{-1}$. This cut-off point could possibly be employed to guide postoperative TCD monitoring where it is not routinely available and could help identify patients where a more aggressive strategy of cardiovascular risk factor reduction could be employed. However, the association of Pocock score with a high rate of postoperative microemboli requiring additional antiplatelet agents was unclear in our cohort, as the score was not significantly associated with an MES rate of $>50$ hour $^{-1}$ when ROC analysis was used. This could be confounded by the fact that the majority of patients in our cohort were already on dual antiplatelet therapy (aspirin and clopidogrel). Payne $e t a l^{30}$ demonstrated that dual antiplatelet agents are effective in minimising the occurrence of postoperative microemboli. A more recent study ${ }^{31}$ reported that with routine use of preoperative dual antiplatelet treatment, the requirement of postcarotid surgery TCD monitoring to identify patients who are at risk of developing thrombotic stroke could be significantly reduced. Taking into account our findings and the aforementioned data on dual antiplatelet therapy, we could argue that postoperative TCD can selectively be used in those with a Pocock score $\geq 2.3 \%$, given that they already receive dual antiplatelet agents. A multicentre prospective observational study is obviously needed to prove and validate this hypothesis.

One of the main limitations of this study is the fact that data were derived from a single centre. However, the cohort is representative of the standard population of patients undergoing carotid surgery, despite the fact that patients were treated in a single centre. The demographic profiles such as age and sex were similar to the expected carotid disease characteristics and consistent with other recent major carotid intervention studies. ${ }^{32} 33$ The baseline cardiovascular risk factors in our cohort were similar to the two most recent multicentre randomised controlled trials on carotid intervention. ${ }^{32}{ }^{33}$ The overall 30-day mortality and morbidity rates, such as cerebrovascular events, myocardial infarction and postoperative bleeding, were similar to the most recent nationwide UK CEA audit. ${ }^{11}$ To date, the association between classical cardiovascular risk factors and microemboli has not been studied. This is the first attempt to evaluate the association between Pocock risk score and presence of microemboli following CEA. Pocock score is the only risk score derived from established CVD cohorts. We looked specifically at a Pocock cut-off value of $2.3 \%$ because our data showed the overall 30-day mortality was $1.9 \%$ (13/670 patients) and 30-day CVA or TIA was 16 (2.4\%), findings which are also similar to the most recent nationwide UK CEA audit. ${ }^{11}$

The proportion of patients who developed microemboli acutely following surgery was similar to a previously published study in a different centre. ${ }^{34}$ Another limitation is the lack of long-term follow-up data. However, this was not part of the study's objectives.

\section{CONCLUSIONS}

A raised Pocock score has an association with and high sensitivity for the presence of microemboli acutely following carotid surgery. These findings suggest that the Pocock cardiovascular risk score could potentially be used as a clinical tool to identify patients who are at increased risk of developing acute postoperative microemboli.

Contributors MS and DRJS conceived the study. All authors were responsible for the design and execution of the study. MS, AS and RWSL were responsible for data collection and data analysis. DRJS, CEH and CHEl are guarantors.

\section{Competing interests None declared.}

Ethics approval Research and Development Department at University Hospitals Coventry and Warwickshire NHS Trust.

Provenance and peer review Not commissioned; externally peer reviewed. Data sharing statement № additional data are available.

Open access This is an open access article distributed in accordance with the Creative Commons Attribution Non Commercial (CC BY-NC 4.0) license, which permits others to distribute, remix, adapt, build upon this work non-commercially, and license their derivative works on different terms, provided the original work is properly cited and the use is non-commercial. See: http://creativecommons.org/ licenses/by-nc/4.0/

(C) Article author(s) (or their employer(s) unless otherwise stated in the text of the article) 2018. All rights reserved. No commercial use is permitted unless otherwise expressly granted. 


\section{REFERENCES}

1. O'Leary DH, Polak JF, Kronmal RA, et al. Carotid-artery intima and media thickness as a risk factor for myocardial infarction and stroke in older adults. Cardiovascular Health Study Collaborative Research Group. N Engl J Med 1999;340:14-22.

2. Bekelis K, Bakhoum SF, Desai A, et al. A risk factor-based predictive model of outcomes in carotid endarterectomy: the National Surgical Quality Improvement Program 2005-2010. Stroke 2013;44:1085-90.

3. Anon. Joint British recommendations on prevention of coronary hear disease in clinical practice: summary. British Cardiac Society, British Hyperlipidaemia Association, British Hypertension Society, British Diabetic Association. BMJ 2000;320:705-8.

4. Pocock SJ, McCormack V, Gueyffier F, et al. A score for predicting risk of death from cardiovascular disease in adults with raised blood pressure, based on individual patient data from randomised controlled trials. BMJ 2001;323:75-81.

5. Markus HS, Thomson ND, Brown MM. Asymptomatic cerebral embolic signals in symptomatic and asymptomatic carotid artery disease. Brain 1995;118(Pt 4):1005-11.

6. Levi CR, O'Malley HM, Fell G, et al. Transcranial Doppler detected cerebral microembolism following carotid endarterectomy. High microembolic signal loads predict postoperative cerebral ischaemia. Brain 1997;120(Pt 4):621-9.

7. King A, Markus HS. Doppler embolic signals in cerebrovascular disease and prediction of stroke risk: a systematic review and metaanalysis. Stroke 2009;40:3711-7.

8. Markus HS, King A, Shipley M, et al. Asymptomatic embolisation for prediction of stroke in the Asymptomatic Carotid Emboli Study (ACES): a prospective observational study. Lancet Neurol 2010;9:663-71.

9. Saedon M, Singer DR, Pang R, et al. Registry report on kinetics of rescue antiplatelet treatment to abolish cerebral microemboli after carotid endarterectomy. Stroke 2013;44:230-3.

10. British Cardiac Society; British Hypertension Society; Diabetes UK; HEART UK; Primary Care Cardiovascular Society; Stroke Association.. JBS 2: Joint British Societies' guidelines on prevention of cardiovascular disease in clinical practice. Heart 2005;91(Suppl 5):v1-52.

11. Carotid Interventions Audit Group. Royal College of Physicians, ed. UK carotid endarterectomy audit. London: CIAS Group, 2012.

12. Naylor AR, Hayes PD, Allroggen $\mathrm{H}$, et al. Reducing the risk of carotid surgery: a 7-year audit of the role of monitoring and quality control assessment. J Vasc Surg 2000;32:750-9.

13. Ringelstein EB, Droste DW, Babikian VL, et al. Consensus on microembolus detection by TCD. International Consensus Group on Microembolus Detection. Stroke 1998;29:725-9.

14. Saedon M, Dilshad A, Tiivas C, et al. Prospective validation study of transorbital Doppler ultrasound imaging for the detection of transient cerebral microemboli. Br J Surg 2014;101:1551-5.

15. Cullinane M, Reid G, Dittrich R, et al. Evaluation of new online automated embolic signal detection algorithm, including comparison with panel of international experts. Stroke 2000;31:1335-41.

16. McClellan KJ, Goa KL. Tirofiban. A review of its use in acute coronary syndromes. Drugs 1998;56:1067-80.

17. https://www.hra.nhs.uk/planning-and-improving-research/policiesstandards-legislation/governance-arrangement-research-ethicscommittees/. accessed 28 Feb 2018.
18. Newman JE, Ali M, Sharpe R, et al. Changes in middle cerebral artery velocity after carotid endarterectomy do not identify patients at high-risk of suffering intracranial haemorrhage or stroke due to hyperperfusion syndrome. Eur J Vasc Endovasc Surg 2013;45:562-71.

19. Gaunt ME, Ratliff DA, Martin PJ, et al. On-table diagnosis of incipient carotid artery thrombosis during carotid endarterectomy by transcranial Doppler scanning. J Vasc Surg 1994;20:104-7.

20. Gaunt ME, Martin PJ, Smith JL, et al. Clinical relevance of intraoperative embolization detected by transcranial Doppler ultrasonography during carotid endarterectomy: a prospective study of 100 patients. Br J Surg 1994;81:1435-9.

21. Spencer MP. Transcranial Doppler monitoring and causes of stroke from carotid endarterectomy. Stroke 1997;28:685-91.

22. Cantelmo NL, Babikian VL, Samaraweera RN, et al. Cerebral microembolism and ischemic changes associated with carotid endarterectomy. J Vasc Surg 1998;27:1024-31.

23. Laman DM, Wieneke $\mathrm{GH}$, van Duijn $\mathrm{H}$, et al. High embolic rate early after carotid endarterectomy is associated with early cerebrovascular complications, especially in women. J Vasc Surg 2002;36:278-84.

24. Gaunt ME, Smith JL, Ratliff DA, et al. A comparison of quality control methods applied to carotid endarterectomy. Eur J Vasc Endovasc Surg 1996;11:4-11.

25. Hayes PD, Payne D, Lloyd AJ, et al. Patients' thromboembolic potential between bilateral carotid endarterectomies remains stable over time. Eur J Vasc Endovasc Surg 2001;22:496-8.

26. Hayes PD, Allroggen $\mathrm{H}$, Steel $\mathrm{S}$, et al. Randomized trial of vein versus Dacron patching during carotid endarterectomy: influence of patch type on postoperative embolization. J Vasc Surg 2001;33:994-1000.

27. Golledge J, Gibbs R, Irving C, et al. Determinants of carotid microembolization. J Vasc Surg 2001;34:1060-4.

28. Stork JL, Levi CR, Chambers BR, et al. Possible determinants of early microembolism after carotid endarterectomy. Stroke 2002;33:2082-5.

29. Hayes PD, Box H, Tull S, et al. Patients' thromboembolic potential after carotid endarterectomy is related to the platelets' sensitivity to adenosine diphosphate. J Vasc Surg 2003;38:1226-31.

30. Payne DA, Jones Cl, Hayes PD, et al. Beneficial effects of clopidogrel combined with aspirin in reducing cerebral emboli in patients undergoing carotid endarterectomy. Circulation 2004;109:1476-81.

31. Sharpe RY, Dennis MJ, Nasim A, et al. Dual antiplatelet therapy prior to carotid endarterectomy reduces post-operative embolisation and thromboembolic events: post-operative transcranial Doppler monitoring is now unnecessary. Eur $J$ Vasc Endovasc Surg 2010;40:162-7.

32. Ederle J, Dobson J, Featherstone RL, et al. Carotid artery stenting compared with endarterectomy in patients with symptomatic carotid stenosis (International Carotid Stenting Study): an interim analysis of a randomised controlled trial. Lancet 2010;375:985-97.

33. Brott TG, Hobson RW, Howard G, et al. Stenting versus endarterectomy for treatment of carotid-artery stenosis. $N$ Engl J Med 2010;363:11-23.

34. Naylor AR, Sayers RD, McCarthy MJ, et al. Closing the loop: a 21year audit of strategies for preventing stroke and death following carotid endarterectomy. Eur J Vasc Endovasc Surg 2013;46:161-70. 